\title{
Physicochemical and Rheological Characterization of an Acidic Milk Product: Kefir Concentration Effect
}

Jorge Octavio Virues Delgadillo, Miguel de Jesús Luna Lara, Claudia Karina Lozada Santillan, Carmen Bulbarela Sampieri and López del Castillo Lozano Micloth

Facultad de Ciencias Químicas, Universidad Veracruzana, Lomas del Estadio S/N, Xalapa, Veracruz 91000, México

\begin{abstract}
The main objective of this study was the analysis of physicochemical and rheological behavior of a drinkable beverage prepared with different concentrations (5\%, $10 \%$ and $20 \% \mathrm{w} / \mathrm{w}$ ) of Kefir. Several rheological models were also evaluated to determine the model that better fit experimental data. Apparent viscosity was measured with a Brookfield Viscometer within shear rates of $0.26 \mathrm{rad} / \mathrm{s}$ to $2.09 \mathrm{rad} / \mathrm{s}$; and with an Ar-2000ex TA Instruments Rheometer within shear rates of $0.01 \mathrm{rad} / \mathrm{s}$ to 1,000 rad/s. Physicochemical tests, such as titratable acidity, chloride percent, fat concentration, color, humidity, syneresis, and total solids, were determined using laboratory equipment. The main result observed in all samples tested with Brookfield viscometer was that Kefir drink behaved as a Newtonian Fluid within shorter strain rates $(0.26 \mathrm{rad} / \mathrm{s}$ to $2.09 \mathrm{rad} / \mathrm{s})$. However, when the same samples were tested with Ar-2000ex Rheometer, a different behavior was observed: Over a wider range of shear rates, the fully non-Newtonian behavior of Kefir samples was discovered. Besides, additional variables such as shear and normal stresses, and loss and storage modulus, were analyzed with Ar-2000ex Rheometer. The rheological model that better fitted the experimental data was Cross model, followed by Power Law Model. Statistical analysis of viscosity data acquired with Brookfield Viscometer from all Kefir concentrations was not significant ( $p$ values greater than 0.05 ); which demonstrated that the effect of Kefir concentration over shorter strain rates was not significant, and thus, the samples behave as a Newtonian fluid. On the other hand, $p$ values lower than 0.05 were observed in most of the different Kefir concentration samples tested with Ar-2000ex Rheometer; which indicates that a statistical significant effect was observed and thus a non-Newtonian behavior of Kefir samples. All statistical analysis was performed with SPSS v.16 software, selecting a Duncan Test with a confident interval of $95 \%$ to accept or reject the variances compared of the different Kefir concentration samples.
\end{abstract}

Key words: Food rheology, viscosity, shear rate, kefir concentration.

\section{Introduction}

Kefir is a fermented drink [1] that contains minerals (calcium, magnesium and phosphorus), vitamins $\mathrm{B}$ and $\mathrm{K}$, lactic acid bacteria and yeast that contributes to maintaining a healthy body. Moreover, proteins in kefir are partially digested and therefore more easily used by the body. Food industry has developed some Kefir based products, however in Central Veracruz communities, like "Las Vigas de Ramirez", local farmers produce Kefir drinks that needs to be characterized and better formulated in order to introduce their products in national and international

Corresponding author: Jorge Octavio Virues Delgadillo, professor, research fields: food rheology and biomaterials mechanical testing. markets. In order to maintain the quality of these products and guarantee its shelf durability, industries rely on chemical and physical techniques that enable them to know the status of the product and at the same time helping them to streamline the production process. Techniques for measuring the rheological properties of food fluids were used for 30 years [2-4]; although most current efforts to measure the rheological behavior of fluids include works of Rao [5], Steffey [6] and Roudot [7]. Rheological characterization of Kefir products is important not only for the design of unit operations, but also for optimization processes and quality assurance of food products [8-11]. For instance, Yovanoudi et al. [8] showed that apparent viscosity was a function of the 
type of starter, fermentation temperature and casein content; Dinkci et al. [9] prepared a fermented drink with $20 \%$, $40 \%$ and $60 \%$ of Kefir grains, and found that the samples made with $20 \%$ of Kefir grains were preferred in the sensorial evaluation; Wang et al. [10] isolated Lactobacillus plantarum from Tibet Kefir in order to increased Kefir fermented drink flavor; and, Glibowski and Zielinska [11] found that Kefir was a viscoelastic material with thixotropic and shear-thinning behavior. Time dependence is related to structural changes due to shear flow. Consequently, time-dependent rheological characterization is extremely important in order to understand the changes that occur in the product during a commercial process. In this work, the effect of Kefir grain concentration (5\%, $10 \%$ and $20 \% \mathrm{w} / \mathrm{w}$ ) over physicochemical and rheological properties of a drinkable acidic milk product was analyzed.

\section{Methodology}

In order to perform physicochemical and rheological tests, Kefir grains and whole bovine milk from "Las Vigas de Ramirez” community were used. Whole milk was pasteurized at $85-95{ }^{\circ} \mathrm{C}$ during 30 minutes, followed by the addition of Kefir grains at 22-25 ${ }^{\circ} \mathrm{C}$ and the incubation of samples for at least 12-16 hours. After that, fermented milk was decanted from the grains, and stored in the fridge at $10^{\circ} \mathrm{C}$ for up to three days before testing. Physicochemical tests, such as titratable acidity, chloride percent, fat concentration, color, humidity, syneresis, and total solids, were determined using laboratory equipment. Titratable acidity and Chloride percent testing were performed using sodium hydroxide $(0.083 \mathrm{~N}$ and 0.1 $\mathrm{N})$ with fenolftaleine, and $5 \%$ silver nitrate with potassium dichromate, respectively. Fat concentration was determined by acidic hydrolysis, where two grams of sample was dissolved in $4 \mathrm{~mL}$ of concentrated chloride acid, and heated up to $90{ }^{\circ} \mathrm{C}$. Then, $5 \mathrm{~mL}$ of eter was added in order to separate light and dense phases and by difference in weights record fat percent. $\mathrm{pH}$ was recorded using a potentiometer calibrated with solutions with $\mathrm{pH} 4$ and 7. Syneresis was performed on a centrifuge at 1,250 rpm for 30 minutes. A colorimeter was used to perform color testing. Humidity was obtained using a dry heater at $105{ }^{\circ} \mathrm{C}$ for nearly 4-6 hours. Total solids were acquired by the use of a melting pot, where water content of each sample was evaporated between 80-100 ${ }^{\circ} \mathrm{C}$ for nearly 24 hours. Apparent viscosity was measured with an Ar-2000ex TA Instruments Rheometer within shear rates of 0.01 to $1,000 \mathrm{rad} / \mathrm{s}$ (Fig. 1); and with a Brookfield Viscometer (Model 4535, Lab-Line Instruments) within shear rates of 0.26 $\mathrm{rad} / \mathrm{s}$ to $2.09 \mathrm{rad} / \mathrm{s}$ (Fig. 2). Viscometer spindles used and its diameters are shown in Fig. 3 and Table 1, respectively. Rheometer testing included three types of experiments: Oscillatory (angular frequency from 1 $\mathrm{rad} / \mathrm{s}$ to $100 \mathrm{rad} / \mathrm{s}$ ), temperature ramp at $5{ }^{\circ} \mathrm{C} / \mathrm{min}$ (10-80 $\left.{ }^{\circ} \mathrm{C}\right)$ and shear rate sweep (steady state flow). Fermented drink samples, prepared with three different Kefir grain concentrations (5\%, 10\% and $20 \% \mathrm{w} / \mathrm{w}$ ), were analyzed by triplicate. Temperature in oscillatory, steady state flow and Brookfield testing were maintained constant at $25{ }^{\circ} \mathrm{C}$. Statistical ANOVA tests were performed using SPSS 16.0 software,

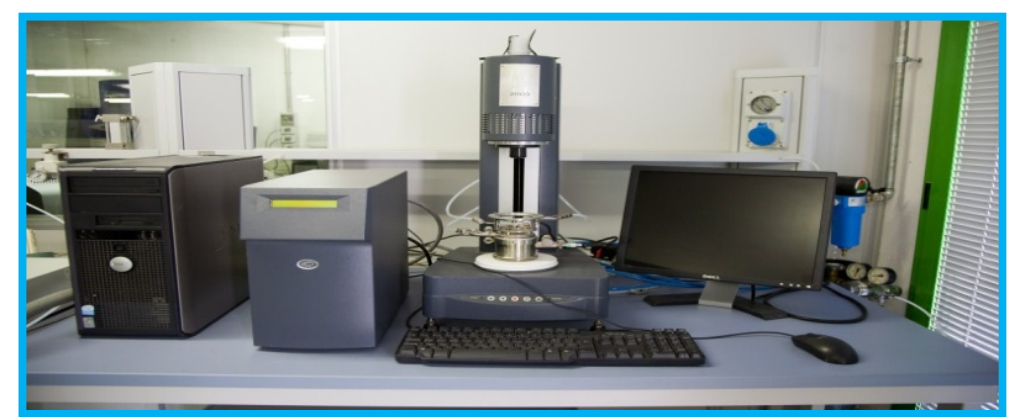

Fig. 1 Ar-2000ex TA Instruments Rheometer. 


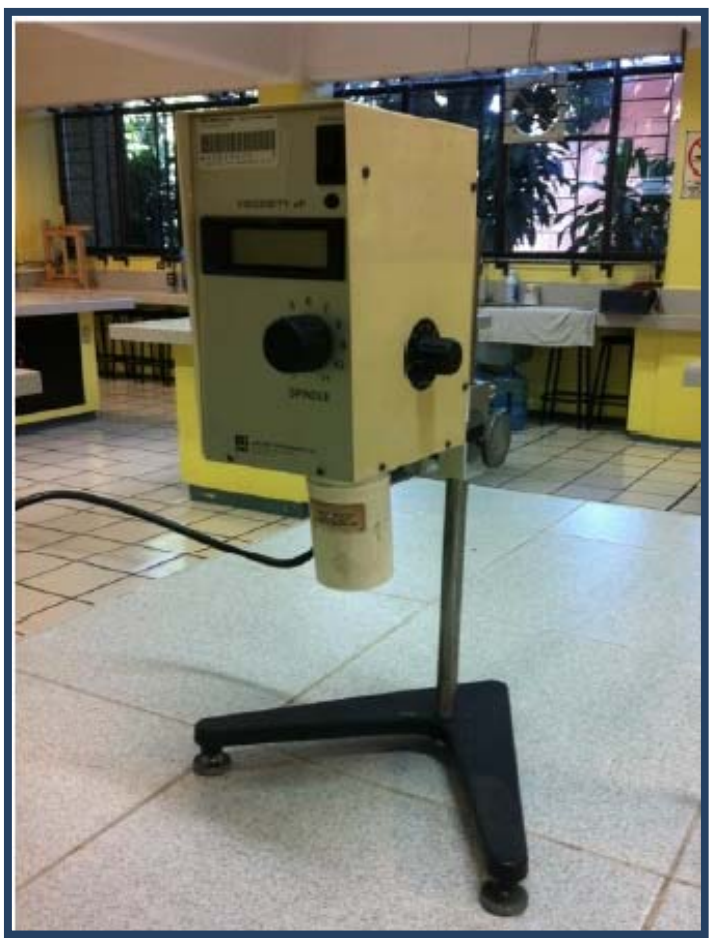

Fig. 2 Brookfield Viscometer.

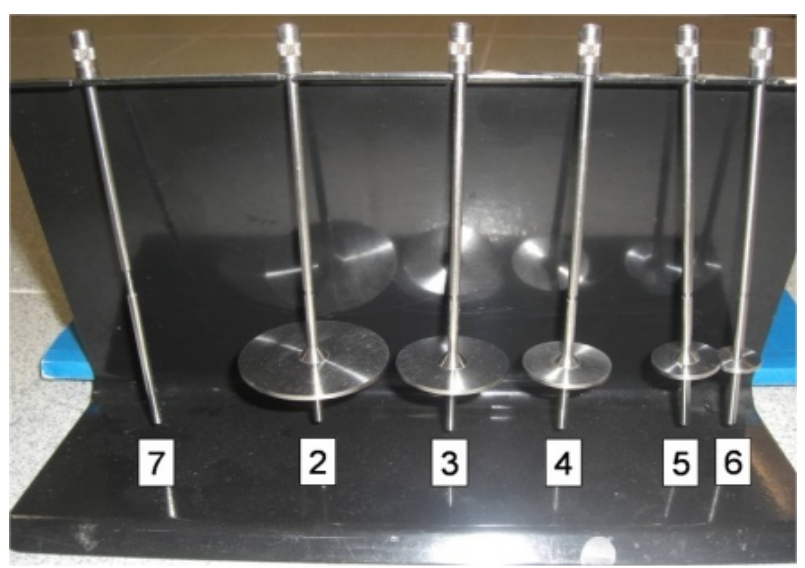

Fig. 3 Brookfield Spindle numbers and geometry.

Table 1 Diameter of Brookfield Spindles.

\begin{tabular}{ll}
\hline Spindle Nr. & Diameter $(\mathrm{cm})$ \\
\hline 2 & 4.7 \\
3 & 3.5 \\
4 & 2.7 \\
5 & 2.1 \\
6 & 1.5 \\
7 & 0.2 \\
\hline
\end{tabular}

where a Duncan test with a confident interval of 95\% was selected to compare the variances from 48 possible combinations of Kefir concentration (5\%, 10\% and 20\% w/w), spindle number (2, 3, 4 and 5) and shear rate $(0.26,0.52,1.05,2.09 \mathrm{rad} / \mathrm{s})$.

\section{Results}

In this paper physicochemical and rheological properties of a drinkable beverage prepared with different concentrations (5\%, 10\% and 20\% w/w) of Kefir were evaluated. All statistical analysis was performed with SPSS v.16 software, selecting a Duncan Test with a confident interval of $95 \%$ to accept or reject the variances compared of the different Kefir concentration samples. Physicochemical properties (Table 2) that were statistically significant ( $p$ values less than 0.05 ) were $\mathrm{pH}$ and specific weight for all samples; meanwhile titratable acidity and color were not statistically significant. Chlorine and syneresis percents, fat and humidity fractions, were statistically different only for one Kefir concentration ( $5 \% \mathrm{w} / \mathrm{w})$. Specific weight increased at higher Kefir concentrations, been 1.2762 \pm 0.0065 at $5 \% \mathrm{w} / \mathrm{w}$ and $1.4338 \pm 0.0077$ at $20 \% \mathrm{w} / \mathrm{w}$. Specific weight of whole milk was 1.028-1.034 g/mL. The same behavior was found in $\mathrm{pH}$ : Higher Kefir concentration increased values of $\mathrm{pH}$ from $3.7743 \pm$ 0.1284 to $5.6257 \pm 0.1653$.

Experimental rheological results are shown in Figs. 4-8, and modeling results are shown in Figs. 9-11. For instance, apparent viscosity as a function of shear rate was obtained in steady state flow (Fig. 4), where an increase in shear rate decreased apparent viscosity of all samples tested, behavior similar of a pseudoplastic fluid. On the other hand, in Oscillatory testing (Fig. 5) it was observed that G' (loss modulus) was higher (up to $13 \mathrm{~Pa}$ ) than $\mathrm{G}$ ' (storage modulus) below angular frequencies of $20 \mathrm{rad} / \mathrm{s}$, and the opposite behavior was found above this angular frequency. The highest values of G' (nearly $38 \mathrm{~Pa}$ ) were obtained above $64 \mathrm{rad} / \mathrm{s}$ for samples with $20 \%$ w/w of Kefir. On temperature sweep tests, shear stress (Fig. 6), apparent viscosity (Fig. 7) and normal stresses (Fig. 8) were increased from the lowest 
Table 2 Physicochemical results.

\begin{tabular}{lllllll}
\hline \multirow{2}{*}{ Physicochemical properties } & \multicolumn{2}{c}{$5 \%$} & \multicolumn{3}{c}{$10 \%$} & \multicolumn{2}{c}{$20 \%$} \\
\cline { 2 - 7 } & Mean & SDev & Mean & SDev & Mean & SDev \\
\hline Titratable acidity (g/L) & 0.0367 & 0.0044 & 0.0354 & 0.0044 & 0.0341 & 0.0039 \\
Chlorine percent & 0.0057 & 0.00007 & 0.0054 & 0.00005 & 0.0056 & 0.00005 \\
Fat fraction & 0.1675 & 0.0354 & 0.0617 & 0.0165 & 0.0969 & 0.0186 \\
pH & 3.7743 & 0.1284 & 4.2157 & 0.0624 & 5.6257 & 0.1653 \\
Specific weight (g/mL) & 1.2762 & 0.0065 & 1.3469 & 0.0230 & 1.4338 & 0.0077 \\
Syneresis percent & 21.257 & 1.2897 & 24.923 & 1.1020 & 25.440 & 1.1062 \\
Color & 0.0356 & 0.0222 & 0.0303 & 0.0205 & 0.0342 & 0.0314 \\
Humidity fraction & 0.0724 & 0.0186 & 0.0380 & 0.0011 & 0.0344 & 0.0091 \\
\hline
\end{tabular}

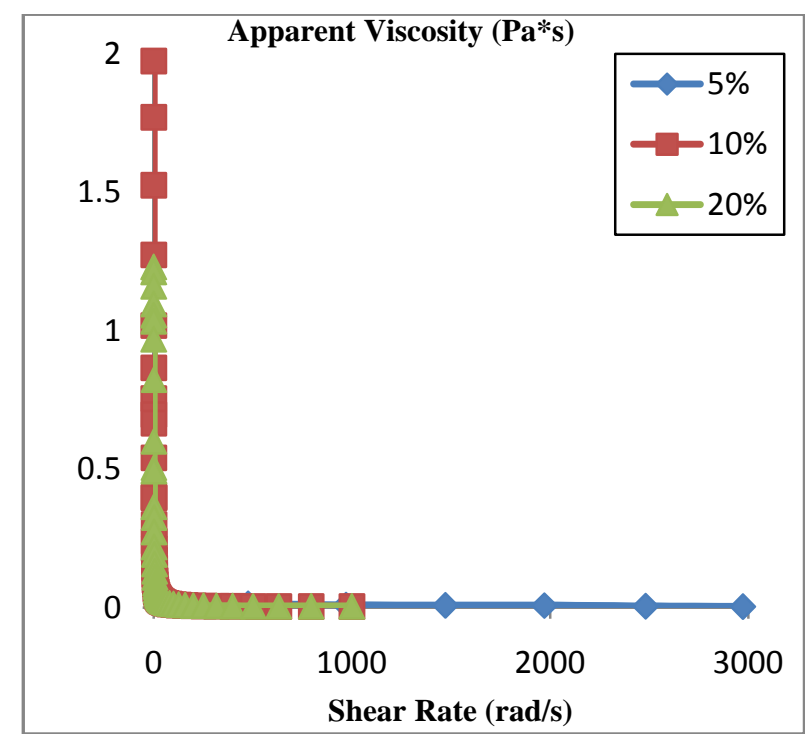

Fig. 4 Steady state flow: apparent viscosity behavior as a function of shear rate.

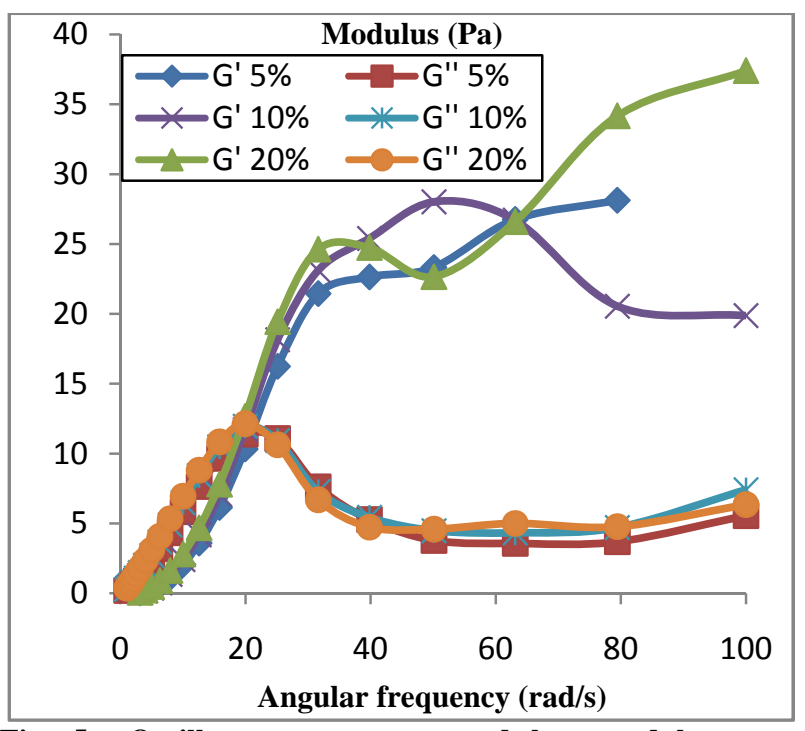

Fig. 5 Oscillatory test: store and loss modulus as a function of angular frequency.

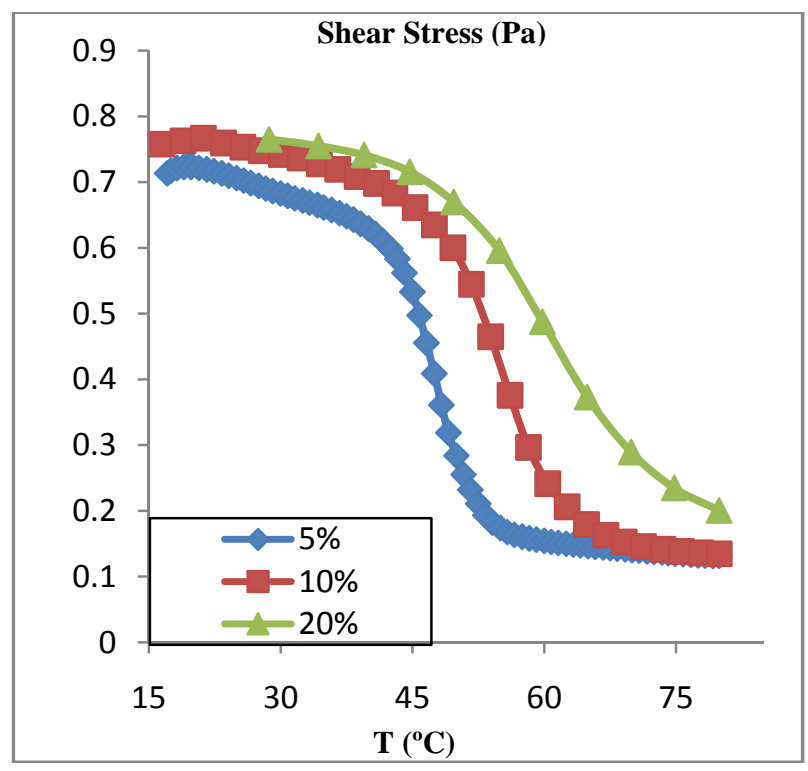

Fig. 6 Temperature sweep test: shear stress effect.

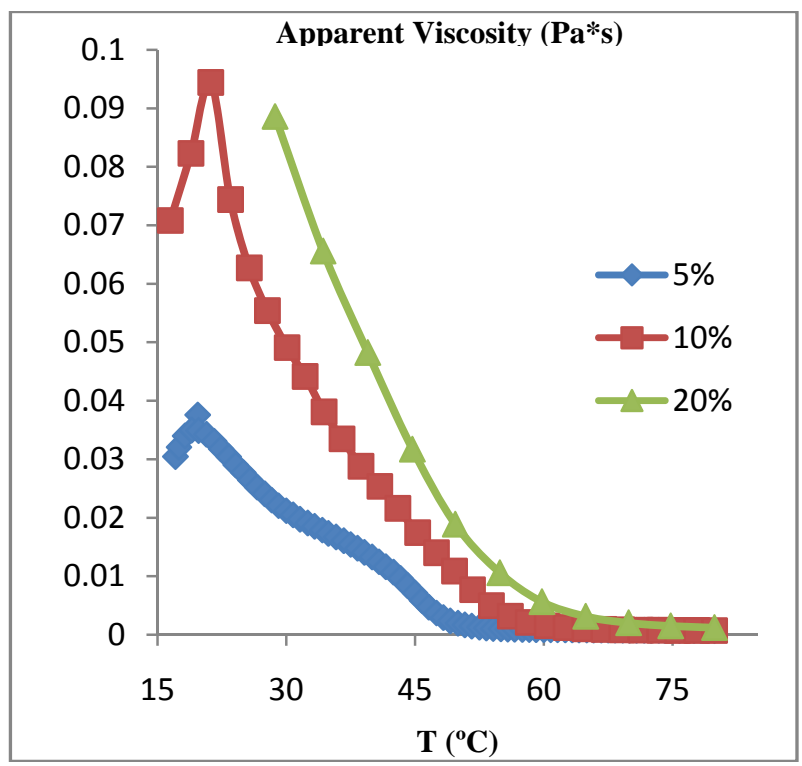

Fig. 7 Temperature sweep test: apparent viscosity effect. 


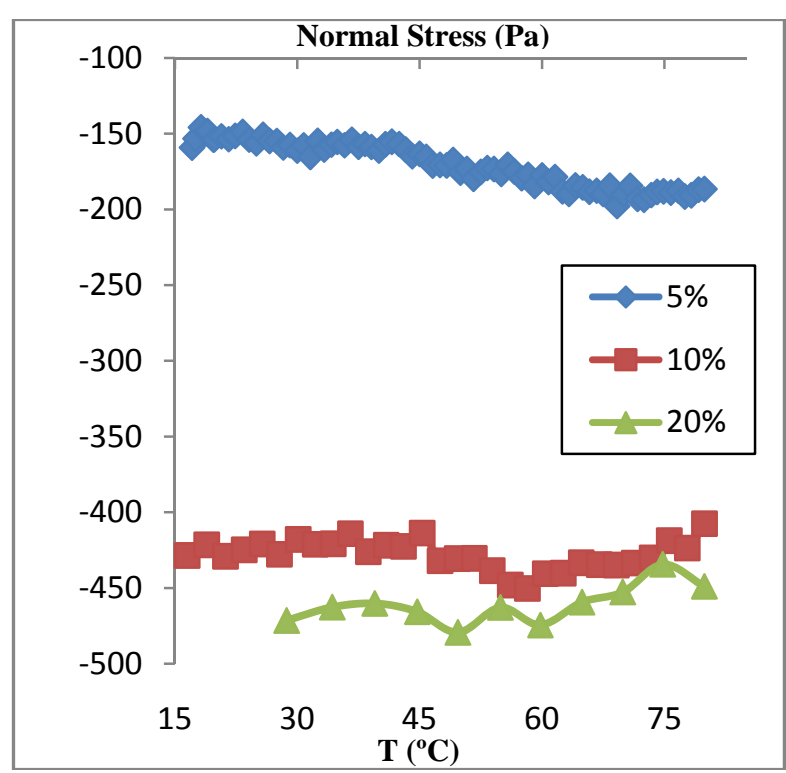

Fig. 8 Normal stresses as a function of temperature.

$(5 \% \mathrm{w} / \mathrm{w})$ to the highest $(20 \% \mathrm{w} / \mathrm{w})$ Kefir concentration. The first two properties decreased dramaticaly as temperature reduction proceed, while normal stresses remain similar as temperature dropped. Solids concentration is one of the main factors that can modify the viscosity [8]. Rheological behavior of $5 \% \mathrm{w} / \mathrm{w}$ samples is lower than $10 \% \mathrm{w} / \mathrm{w}$ samples, and the latter is also lower than $20 \% \mathrm{w} / \mathrm{w}$ Kefir concentration samples; which may be due to viscoelastic properties of the strongest network that might be present in $20 \% \mathrm{w} / \mathrm{w}$ Kefir acidic milk samples. This might be the reason why $20 \% \mathrm{w} / \mathrm{w}$ Kefir acidic milk developed higher values (i.e. shear stress, apparent viscosity, G' and G', modulus) for all rheological testing. Some of the best fitted parameters obtained are shown in Table 3 and Figs. 9-11. In most cases, Cross model, followed by Carreau model, were the rheological models that better fitted the experimental data.

Brookfield viscometer results are summarized in Tables 4-6. As it is shown in Table 4, apparent viscosities of all samples were not significantly different as the shear rates change between $0.26 \mathrm{rad} / \mathrm{s}$ to $2.09 \mathrm{rad} / \mathrm{s}$. Moreover, spindle geometry was only significantly different for two groups: Smaller spindle diameters developed apparent viscosities below $1.5409 \mathrm{~Pa}^{*}$ s and bigger spindle diameters developed apparent viscosities higher than $1.6205 \mathrm{~Pa}^{*}$ s. On the other hand, in Table 6 the effect of Kefir concentration on apparent viscosity is shown. For instance, the lowest value (0.9096 $\left.\mathrm{Pa}^{*} \mathrm{~s}\right)$ was obtained for $5 \%$ Kefir concentration, followed by $10 \%\left(1.3770 \mathrm{~Pa}^{*} \mathrm{~s}\right)$. The highest apparent viscosities (2.4831 $\left.\mathrm{Pa}^{*} \mathrm{~s}\right)$ were observed at $20 \%$ Kefir concentration. Thus, an increase on Kefir concentration increases apparent viscosity up to 2.5 times (when 5\% and 20\% viscosities were compared). 12 different groups were determined using Duncan statistical test, from 48 possible combinations of Kefir concentration (5\%, 10\% and $20 \% \mathrm{w} / \mathrm{w})$, spindle number (2, 3, 4 and 5 ) and shear rate $(0.26,0.52,1.05,2.09 \mathrm{rad} / \mathrm{s})$. The lowest apparent viscosity obtained with Brookfield viscometer was $0.8221 \mathrm{~Pa}^{*} \mathrm{~s}$ at shear rate of $0.26 \mathrm{rad} / \mathrm{s}$, Kefir concentration of 5\% w/w and spindle number 2; and the highest apparent viscosity was $2.7184 \mathrm{~Pa}^{*} \mathrm{~s}$ at shear rate of $1.05 \mathrm{rad} / \mathrm{s}$, Kefir concentration of $20 \%$ w/w and spindle number 4 .

Table 3 Modeling results with some of the constitutive equations selected.

\begin{tabular}{|c|c|c|c|c|c|c|c|}
\hline Model & $\begin{array}{l}\text { Yield stress } \\
(\mathrm{Pa})\end{array}$ & $\begin{array}{l}\text { Viscosity } \\
\left(\mathrm{Pa}^{*} \mathrm{~s}\right)\end{array}$ & Rate index & $\begin{array}{l}\text { Zero rate } \\
\text { viscosity }\left(\mathrm{Pa}^{2} \mathrm{~s}\right)\end{array}$ & $\begin{array}{l}\text { Infinite rate } \\
\text { viscosity }\left(\mathrm{Pa}^{*} \mathrm{~s}\right)\end{array}$ & $\begin{array}{l}\text { Consistency } \\
\text { (s) }\end{array}$ & $\begin{array}{l}\text { Standard } \\
\text { error }\end{array}$ \\
\hline Cross & & & 0.9031 & 0.7756 & $2.742 \mathrm{E}^{-3}$ & 1.689 & 17.90 \\
\hline Carreau & & & 0.8156 & 0.5835 & $2.282 \mathrm{E}^{-3}$ & 1.852 & 20.92 \\
\hline Ellis & & & 4.004 (stress index) & 0.5437 & $4.061 \mathrm{E}^{-3}$ & $2.9621(1 / \mathrm{Pa})$ & 28.97 \\
\hline Williamson & & & 0.7048 & 1.4530 & & 8.620 & 33.82 \\
\hline Casson & 0.2785 & $2.039 \mathrm{E}^{-3}$ & & & & & 35.29 \\
\hline Hershell-Bulkley & 0.3081 & $0.0232 \mathrm{E}^{-3}$ & 0.7238 & & & & 39.79 \\
\hline Sisko & & & 0.3467 & & $3.750 \mathrm{E}^{-3}$ & 0.239 & 40.33 \\
\hline Bingham & 0.4162 & $3.696 \mathrm{E}^{-3}$ & & & & & 47.20 \\
\hline Power law & & 0.1332 & 0.4676 & & & & 54.58 \\
\hline
\end{tabular}




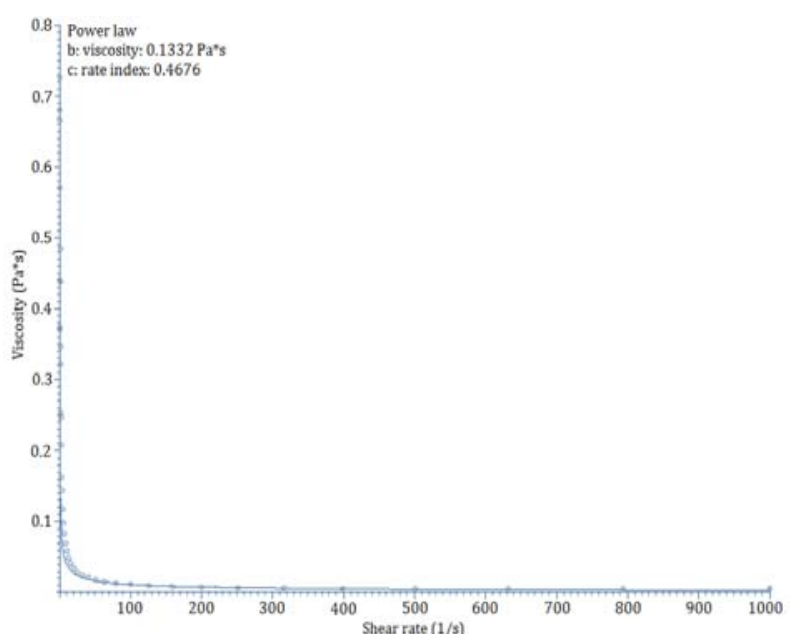

Fig. 9 Power law model fitted parameters $(5 \% \mathrm{w} / \mathrm{w}$ sample).

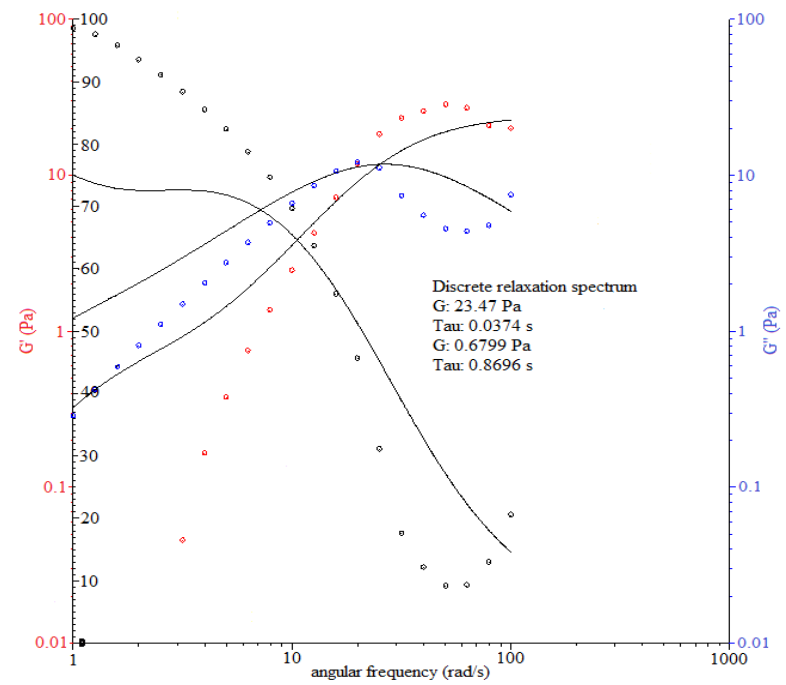

Fig. 10 Oscillation testing fitted parameters $(10 \% \mathrm{w} / \mathrm{w}$ sample). Discrete relaxation spectrum.

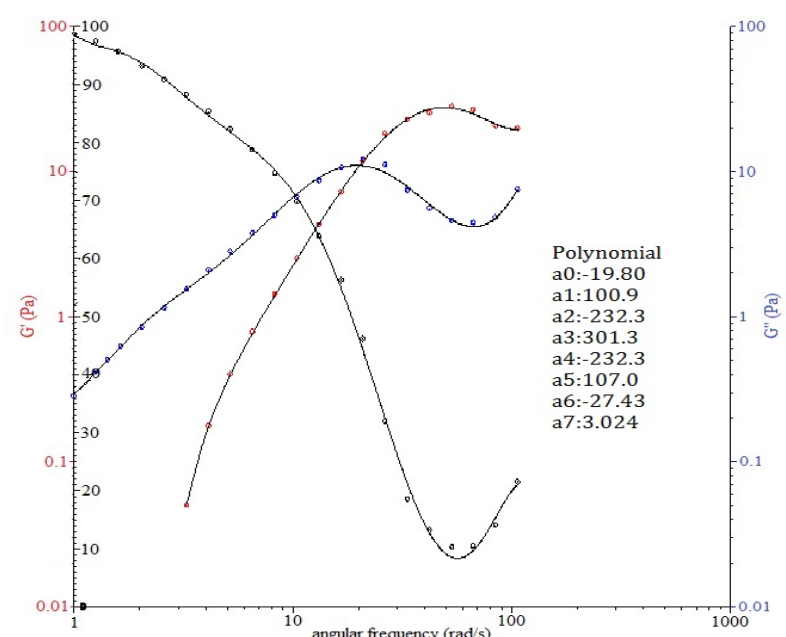

Fig. 11 Oscillation testing fitted parameters $(10 \% \mathrm{w} / \mathrm{w}$ sample). Polynomial fit.
Table 4 Apparent viscosity (Pa*s) results as a function of shear rate (Duncan test).

\begin{tabular}{lll}
\hline Shear rate & $\mathrm{N}$ & Subset \\
\cline { 3 - 3 } & & 1 \\
\hline 0.52 & 330 & 1.5604 \\
0.26 & 177 & 1.5893 \\
1.05 & 660 & 1.5928 \\
2.09 & 1320 & 1.5959 \\
$p$ value & & .531 \\
\hline
\end{tabular}

Means for groups in homogeneous subsets are displayed. The error term is Mean Square (Error) $=469.390$.

Table 5 Apparent viscosity ( $\mathrm{Pa}^{*}$ s) results as a function of spindle number (Duncan test).

\begin{tabular}{llll}
\hline \multirow{2}{*}{ Spindle number } & $\mathrm{N}$ & \multicolumn{2}{c}{ Subset } \\
\cline { 3 - 4 } & & 1 & 2 \\
\hline 2 & 567 & 1.5021 & \\
3 & 567 & 1.5409 & \\
4 & 675 & & 1.6205 \\
5 & 678 & & 1.6739 \\
$p$ value & & .318 & .170 \\
\hline
\end{tabular}

Means for groups in homogeneous subsets are displayed. The error term is Mean Square (Error) $=465.039$.

Table 6 Apparent viscosity (Pa*s) results as a function of Kefir concentration (Duncan test).

\begin{tabular}{lllll}
\hline \multirow{2}{*}{$\begin{array}{l}\text { Kefir concentration } \\
(\mathrm{w} / \mathrm{w})\end{array}$} & $\mathrm{N}$ & \multicolumn{3}{c}{ Subset } \\
\cline { 3 - 5 } & & 1 & 2 & 3 \\
\hline 5 & 829 & 0.9096 & & \\
10 & 829 & & 1.3770 & \\
20 & 829 & & & 2.4831 \\
$p$ value & & 1.000 & 1.000 & 1.000 \\
\hline
\end{tabular}

Means for groups in homogeneous subsets are displayed. The error term is Mean Square (Error) $=33.515$.

\section{Conclusions}

It was showed that Kefir acidic milk beverage might have the characteristics of a pseudoplastic fluid since apparent viscosity decreased as shear rate was increased. In oscillatory testing, it was observed that G' ' was higher than G' below angular frequencies of $20 \mathrm{rad} / \mathrm{s}$, and the opposite behavior was found above this angular frequency. Samples with the highest Kefir concentration developed the highest values of storage modulus at angular frequencies above $64 \mathrm{rad} / \mathrm{s}$; this behavior might be due to strongest crosslinked network that probably is present at $20 \% \mathrm{w} / \mathrm{w}$. It was 
also observed that shear stress and apparent viscosity decreased as temperature reduction proceeds. 20\% w/w Kefir acidic milk developed higher values (i.e. shear stress, apparent viscosity, G' and G' modulus) for all rheological testing. In relation with physicochemical properties, only specific weight and $\mathrm{pH}$ were statistically significant as a function of Kefir concentration, where the lowest and highest values were found at $5 \%$ and $20 \% \mathrm{w} / \mathrm{w}$, respectively. The constitutive equations that best fitted experimental data were Cross and Carreau models. Finally, Brookfield results showed that Kefir samples behaved like a Newtonian fluid between shear rates of 0.26 $\mathrm{rad} / \mathrm{s}$ and $2.09 \mathrm{rad} / \mathrm{s}$; geometry was only statistically significant between small and big spindle diameters; and apparent viscosity increase as a function of Kefir concentration. When Kefir drink is at rest, it has a gel-dimensional microstructure. By applying a shear stress, agitation generates the microstructure breakdown in linear chains as time passes, breaking the physical links, thereby causing a decrease in viscosity.

\section{References}

[1] Wastra, F. S. 2001. "Mundo láctico y fermentación." Diario de ciencias lecheras para la ingeniería UAM 2031: 4-10.
[2] Rao, M. A. 1977. "Rheology of Liquid Foods-A Review.” J. Texture Stud. 8: 135-68.

[3] Muller, H. G. 1973. Introducción a la Reología de los Alimentos. 1a Edición, Editorial Acribia, Zaragoza España.

[4] Bourne, M. C. 1982. Food Texture and Viscosity. San Diego, California: Academic Press.

[5] Rao, M. A. 2005. "Rheological Properties of Fluid Foods." In Engineering Properties of Food, 3rd ed., edited by Rao, M. A., Rizvi, S. S. H., and Datta, A. K. Boca Ratón, FL, USA: CRC Press, 41-99.

[6] Steffe, J. F. 1996. Rheological Methods in Food Process Engineering. 2a Edición, USA: Freeman Press.

[7] Roudot, A. C. 2004. Reología y Análisis de la Textura de los Alimentos. 1st ed. Editorial Acribia, Zaragoza, España.

[8] Yovanoudi, M., Dimitreli, G., Raphaelides, S. N., and Antoniou, K. D. 2013. "Flow Behavior Studies of Kefir Type Systems.” Journal of Food Engineering 118 (1): 41-8.

[9] Dinkci, N., Kesenkas, H., Korel, F., and Kinik, O. 2015. "An Innovative Approach: Cow/Oat Milk Based Kefir.” Agriculture, Dairy \& Animal Science 65 (3): 177-86.

[10] Wang, J., Zhao, X., Tian, Z., He, C. C., Yang, Y. W., and Yang, Z. N. 2015. "Isolation and Characterization of Exopolysaccharide-Producing Lactobacillus Plantarum SKT109 from Tibet Kefir.” Polish Journal of Food and Nutrition Sciences 65 (4): 269-79.

[11] Glibowski, P., and Zielinska, E. 2015. "Physicochemical and Sensory Properties of Kefir Containing Inulin and Oligofructose." International Journal of Dairy Technology 68 (4): 602-7. 